Tropical Journal of Pharmaceutical Research June 2012; 11 (3): 351-359

(C) Pharmacotherapy Group, Faculty of Pharmacy, University of Benin

Benin City, 300001 Nigeria.

All rights reserved.

Available online at http://www.tjpr.org

Research Article

http://dx.doi.org/10.4314/tjpr.v11i3.3

\title{
Preparation and In-vitro Evaluation of Gastroretentive Bupropion Hydrochloride Tablets
}

\author{
Farnaz Fouladi and Seyed Alireza Mortazavi*
}

Department of Pharmaceutics, School of Pharmacy, Shahid Beheshti University of Medical Sciences, Tehran, Iran.

\begin{abstract}
Purpose: To develop a gastroretentive formulation of bupropion hydrochloride in the form of floating tablets.

Methods: Floating tablets were prepared by wet granulation method using various amounts of sodium carboxymethycellulose ( $\mathrm{NaCMC}$ ), different molecular weight grade of hydroxypropyl methylcellulose (HPMC) and varying amounts of fillers (microcrystalline cellulose, lactose and tricalcium phosphate). Sodium bicarbonate was also incorporated as the gas-generating agent. The formulations were tested for their physical properties, floating lag time, duration of floating and in-vitro drug release.

Results: All the tablet formulations containing either HPMC K4M or HPMC K15M as the sustainedrelease polymer together with either microcrystalline cellulose (MCC) or lactose, floated in the release medium for $>10 \mathrm{~h}$. Tablets prepared with MCC released $\geq 79 \%$ of the drug after $10 \mathrm{~h}$, while those prepared with lactose released $\geq 85 \%$ of the drug within the same period. Tablets containing NaCMC alone did not show good floating properties but when HPMC K4M was also incorporated at certain ratios, tablets with good floating behavior and suitable drug release patterns were produced. Drug release kinetic studies showed that formulations fitted best to the Higuchi model.

Conclusion: The developed floating tablets of bupropion $\mathrm{HCl}$ exhibited prolonged drug release for $\geq 10$ $h$, and, thus may improve bioavailability and minimize fluctuations in plasma drug concentration.
\end{abstract}

Keywords: Bupropion HCl, Floating tablets, hydroxypropylmethylcellulose, Sodium carboxymethylcellulose, Microcrystalline cellulose, Lactose, Tricalcium phosphate, Drug release.

*Corresponding author: Email: mortazavisar@yahoo.com; Tel: +9821-88209623. 


\section{INTRODUCTION}

One of the problems associated with oral sustained release systems is that they do not remain for long in the upper gastrointestinal tract (GIT) which is the main absorption region for most drugs. Thus, rapid gastrointestinal transit can prevent complete drug release in the absorption zone and this may lead to reduction in drug bioavailability and efficacy of administered dose [1]. However, the development of gastroretentive drug delivery systems (GRDDS) can overcome this problem. GDDS are capable of being retained in the stomach for a long period of time while they release the drug in a sustained manner for continuous delivery to its absorption site in the upper GIT [2].

Various approaches have been employed to increase the retention of oral dosage forms in the stomach. One of the most common approaches is to formulate floating drug delivery systems (FDDS) [3]. FDDS have a bulk density lower than gastric fluids and thus remain buoyant in the stomach without affecting the gastric emptying time for a prolonged time [4].

Bupropion is a atypical antidepressant widely used in major depressive disorders and smoking recession [5]. In the treatment of depression, multiple dosing is required. Many of its adverse effects are dose-dependent, and hence a prolonged-release dosage form would improve patient compliance and tolerability. Moreover, it is expected that a gastroretentive dosage form of bupropion $\mathrm{HCl}$ would provide more predictable bioavailability and better control of the fluctuations in drug plasma concentrations.

The objective of the present study was to develop bupropion $\mathrm{HCl}$ floating matrix tablets for prolonged retention and drug release in the stomach, as well as for improved drug availability and reduced fluctuation of the drug in plasma.

\section{EXPERIMENTAL}

\section{Materials}

Bupropion $\mathrm{HCl}$ (Eczacibazsi, Turkey) and HPMC (Methocel K4M, K15M Colorcon, England) were used as drug and matrix former, respectively..NaCMC (3000 cps), lactose, tricalcium phosphate, polyvinylpyrrolidone $\mathrm{K}-10, \quad$ sodium bicarbonate and magnesium stearate were all obtained from Merck, Germany. Microcrystalline cellulose (Avicel PH 102) was produced by FMC Corporation.

\section{Preparation and characterization of matrix tablets}

Matrix tablets containing $150 \mathrm{mg}$ bupropion $\mathrm{HCl}$ powder along with various amounts of HPMC K4M, HPMC $15 \mathrm{M}$ or NaCMC plus fillers (MCC, lactose and tricalcium phosphate) were prepared (as per the compositions in Tables 1 and 2) by compression in a single-punch tablet machine (Erweka, Germany) equipped with $12 \mathrm{~mm}$ flat-faced punches. Since bupropion $\mathrm{HCl}$ shows poor compressibility and flowability, wet granulation was used to prepare the tablets. For this purpose, ethanol $96 \% \mathrm{v} / \mathrm{v}$ was employed as the granulation fluid while polyvinylpyrrolidone (PVP K10 was the binder. The other ingredients added to the formulation are sodium bicarbonate as gas-generating agent and magnesium stearate as lubricant. To prepare the tablets, bupropion $\mathrm{HCl}$ was mixed with all the ingredients, except magnesium stearate, in a mortar. Next, alcohol solution of PVP (10 $\% w / v)$ was added dropwise until a suitable mass for granulation was obtained, after which the wet mass was granulated through a $707 \mu \mathrm{m}$ aperture sieve. The granules obtained were dried in an oven at $40{ }^{\circ} \mathrm{C}$ for 1 h, passed through a $595 \mu \mathrm{m}$ aperture sieve, blended with $0.5 \%$ magnesium stearate and then compressed into tablets of approximately $400 \mathrm{mg}$ each and hardness of $6-8 \mathrm{kP}$. 
Table 1: Composition $(\mathrm{mg})$ of $150 \mathrm{mg}$ bupropion $\mathrm{HCl}$ matrix tablets containing only $\mathrm{HPMC}$ as matrix former*

\begin{tabular}{|c|c|c|c|c|c|c|c|c|c|c|c|c|c|c|c|c|}
\hline Ingredients & $A_{1}$ & $A_{2}$ & $A_{3}$ & $B_{1}$ & $\mathrm{~B}_{2}$ & $\mathrm{~B}_{3}$ & $\mathrm{C}_{1}$ & $\mathrm{C}_{2}$ & $\mathrm{C}_{3}$ & $D_{1}$ & $\mathrm{D}_{2}$ & $D_{3}$ & $E_{1}$ & $E_{2}$ & $F_{1}$ & $F_{2}$ \\
\hline $\begin{array}{l}\text { HPMC } \\
\text { K4M }\end{array}$ & 60 & 80 & 100 & & & & 60 & 80 & 100 & & & & 60 & 80 & & \\
\hline $\begin{array}{l}\text { HPMC } \\
\text { K15M }\end{array}$ & & & & 60 & 80 & 100 & & & & 60 & 80 & 100 & & & 60 & 80 \\
\hline Avicel & 158 & 138 & 118 & 158 & 138 & 118 & & & & & & & & & & \\
\hline Lactose & & & & & & & 158 & 138 & 118 & 158 & 138 & 118 & & & & \\
\hline $\begin{array}{l}\text { Tricalcium } \\
\text { phosphate }\end{array}$ & & & & & & & & & & & & & 158 & 138 & 158 & 138 \\
\hline
\end{tabular}

Table 2: Composition $(\mathrm{mg})$ of $150 \mathrm{mg}$ bupropion $\mathrm{HCl}$ matrix tablet containing $\mathrm{NaCMC}$ or $\mathrm{NaCMC} / \mathrm{HPMC}$ as matrix former

\begin{tabular}{|c|c|c|c|c|c|c|c|c|}
\hline Ingredients & $\mathrm{G}_{1}$ & $\mathrm{G}_{2}$ & $\mathrm{G}_{3}$ & $\mathrm{G}_{4}$ & $\mathrm{H}_{1}$ & $\mathrm{H}_{2}$ & $\mathrm{H}_{3}$ & $\mathrm{H}_{4}$ \\
\hline $\mathrm{NaCMC}$ & 218 & 160 & 120 & 80 & 75 & 60 & 50 & 25 \\
\hline $\begin{array}{l}\text { HPMC } \\
\text { K4M }\end{array}$ & & & & & 25 & 40 & 50 & 50 \\
\hline Avicel & 0 & 58 & 98 & 138 & 118 & 118 & 118 & 118 \\
\hline
\end{tabular}

* Each tablet contained $10 \mathrm{mg}$ sodium bicarbonate and $2 \mathrm{mg}$ magnesium stearate

Tablet friability was determined using 15 tablets from each formulation in an Erweka TA Roche-type friabilitor at a speed of $25 \mathrm{rpm}$ for $4 \mathrm{~min}$. The hardness of 10 tablets was evaluated with an Erweka TBH 28 hardness tester, while the mean thickness of 10 tablets was measured using a caliper.

\section{In vitro buoyancy studies}

In vitro buoyancy of the tablets was determined by measuring floating lag time and duration of floating, according to the method described by Rosa et al [6]. In this method, one tablet was placed in a beaker containing $100 \mathrm{ml}$ of $0.1 \mathrm{M} \mathrm{HCl}$. The time required for the tablet to rise to the surface was considered as the floating lag time. The total time that the tablet remained floating on the surface was also taken as duration of floating. These tests were carried out on 5 tablets per formulation.

\section{In vitro dissolution studies}

Drug release studies were performed on only the formulations that show suitable floating behavior. The test carried out in $900 \mathrm{ml}$ of $0.1 \mathrm{M} \mathrm{HCl}$ using a dissolution tester (Erweka, Germany) USP 23 type 2 apparatus (paddle method), at $50 \mathrm{rpm}$ and $37^{\circ} \mathrm{C}$. Samples (3 $\mathrm{ml}$ each) were taken hourly for $10 \mathrm{~h}$ while keeping the dissolution medium volume constant by replenishing the dissolution medium with an equivalent amount of fresh medium to that withdrawn. The samples were filtered through a $0.45 \mu \mathrm{m}$ membrane filter (Whatman no. 1) and diluted to a suitable concentration with $0.1 \mathrm{M} \mathrm{HCl}$. The absorbance of the samples was measured at $252.5 \mathrm{~nm}$ using a Shimadzu UV-1201 spectrophotometer. Cumulative drug release was calculated from the calibration curve of the drug standard. The results were expressed as mean \pm standard deviation $(\mathrm{SD}, \mathrm{n}=6)$. 


\section{Release kinetics}

In order to determine drug release kinetics, the release data were fitted to various kinetic models - zero order [7], first order [8], Higuchi [9] and Hixon-Crowell [10] as shown in Eqs 1 -4 , respectively.

$$
\mathrm{Q}_{\mathrm{t}}=\mathrm{k}_{0} . \mathrm{t}
$$

where $Q_{t}$ is the $\%$ drug release at time $t$ and $\mathrm{K}_{0}$ is the release rate constant.

$$
\ln (100-Q)=\ln 100-k_{1} \cdot t
$$

where $Q$ is \% drug release and $K_{1}$ is release rate constant.

$$
Q=K_{H} \cdot t^{1 / 2}
$$

where $Q$ is \% drug release and $K_{H}$ is Higuchi release rate constant.

$$
(100-Q)^{1 / 3}=100^{1 / 3}-K_{H C} . t
$$

where $Q$ is \% drug release and $K_{H C}$ is HixonCrowell rate constant.

Furthermore, a simple semi-empirical model (Korsemeyer-Peppas) was used to determine the drug release mechanism for the matrix tablets systems [11], as indicated in Eq 5.

$$
\log \left(\frac{Q_{t}}{Q_{\infty}}\right)=n \log t+\log k_{k p}
$$

where $Q_{t}$ is the amount of the released drug at time $t, Q_{\infty}$ is the overall amount of drug (the whole dose), $\mathrm{k}_{\mathrm{kp}}$ is the constant incorporating the structural and geometric characteristics of the controlled release device, and $n$ is the release exponent indicative of drug release mechanism. For cylindrical geometries such as tablets $\mathrm{n}=0.45$ corresponds to Fickian diffusion, $0.45<\mathrm{n}<0.89$ to non-Fickian (anomalous) diffusion and $\mathrm{n}=0.89$ to case 2 diffusion [12].

In fitting data to the models, only points within the $10-60 \%$ drug release range were used, except for the Higuchi model where the range was $10-70 \%$.

\section{Statistical analysis}

All the results were expressed as mean values \pm standard deviation (SD). Singlefactor analysis of variance (ANOVA) with a Tukey post-hoc test, at $5 \%$ significance level, was used to compare buoyancy and drug release data. The analyses were performed using SPSS 17.0 software.

\section{RESULTS}

\section{Physical properties of bupropion tablets}

The hardness of all the tablet formulations ranged from 6 - $8 \mathrm{kP}$ except for formulation $\mathrm{G}_{1}$ which contained $54.5 \% \mathrm{NaCMC}$ that exhibited a hardness of $5.3 \mathrm{kP}$. The friability of the tablets were within USP 23 limits [13], being $<1 \%$. The thickness of the tablets ranged from $3.10-3.64 \mathrm{~mm}$.

\section{Buoyancy of tablets}

Buoyancy data are presented in Tables 3 and 4.

Table 3: Floating lag time and duration of floating of bupropion tablets containing HPMC as matrix former (mean $\pm \mathrm{SD}, \mathrm{n}=5$ )

\begin{tabular}{lcccccccccccc}
\hline $\begin{array}{l}\text { Floating } \\
\text { properties }\end{array}$ & $\mathbf{A}_{\mathbf{1}}$ & $\mathbf{A}_{\mathbf{2}}$ & $\mathbf{A}_{\mathbf{3}}$ & $\mathbf{B}_{\mathbf{1}}$ & $\mathbf{B}_{\mathbf{2}}$ & $\mathbf{B}_{\mathbf{3}}$ & $\mathbf{C}_{\mathbf{1}}$ & $\mathbf{C}_{\mathbf{2}}$ & $\mathbf{C}_{\mathbf{3}}$ & $\mathbf{D}_{\mathbf{1}}$ & $\mathbf{D}_{\mathbf{2}}$ & $\mathbf{D}_{\mathbf{3}}$ \\
\hline & & & & & & & & & & & \\
Floating & 7.42 & 3.50 & 6.34 & 11.00 & 4.68 & 13.70 & 7.96 & 10.44 & 327.80 & 9.39 & 7.72 & 50.80 \\
lag time & \pm 2.38 & \pm 0.26 & \pm 0.44 & \pm 2.66 & \pm 0.33 & \pm 3.05 & \pm 1.78 & \pm 1.35 & \pm 43.12 & \pm 1.64 & \pm 0.97 & \pm 8.93 \\
(s) & & & & & & & & & & & & \\
$\begin{array}{l}\text { Duration of } \\
\text { floating (h) }\end{array}$ & $>10$ & $>10$ & $>10$ & $>10$ & $>10$ & $>10$ & $>10$ & $>10$ & $>10$ & $>10$ & $>10$ & $>10$ \\
\hline
\end{tabular}


Table 4: Floating lag time and duration of floating of bupropion tablets containing $\mathrm{NaCMC}$ or $\mathrm{NaCMC} / \mathrm{HPMC}$ as matrix former (mean $\pm \mathrm{SD}, \mathrm{n}=5$ ).

\begin{tabular}{|c|c|c|c|c|c|c|c|c|c|c|c|c|}
\hline $\begin{array}{l}\text { Floating } \\
\text { properties }\end{array}$ & $E_{1}$ & $E_{2}$ & $F_{1}$ & $\mathbf{F}_{2}$ & $\mathbf{G}_{1}$ & $\mathbf{G}_{2}$ & $\mathbf{G}_{3}$ & $\mathbf{G}_{4}$ & $\mathrm{H}_{1}$ & $\mathrm{H}_{2}$ & $\mathrm{H}_{3}$ & $\mathbf{H}_{4}$ \\
\hline $\begin{array}{l}\text { Floating } \\
\text { lag time } \\
\text { (s) }\end{array}$ & $-{ }^{a}$ & $-{ }^{a}$ & $-{ }^{a}$ & $-{ }^{a}$ & $-{ }^{a}$ & $\begin{array}{r}1051 \\
\pm 120\end{array}$ & $\begin{array}{r}14.50 \\
\pm 1.50\end{array}$ & $\begin{array}{c}2.33 \\
\pm 0.58\end{array}$ & $\begin{array}{c}1690 \\
2\end{array}$ & $\begin{array}{l}28.26 \\
\pm 2.49\end{array}$ & $\begin{array}{r}14.25 \\
\pm 3.68\end{array}$ & $\begin{array}{c}9.60 \\
\pm 1.23\end{array}$ \\
\hline $\begin{array}{l}\text { Duration } \\
\text { of } \\
\text { floating(h) }\end{array}$ & --- & --- & -- & $\begin{array}{l}-- \\
-\end{array}$ & --- & $\begin{array}{c}2.86 \\
\pm 0.73\end{array}$ & $\begin{array}{c}4.23 \\
\pm 0.56\end{array}$ & Disintegrated $^{\mathrm{b}}$ & $\begin{array}{r}3.20 \\
\pm 0.50\end{array}$ & $>10$ & $>10$ & $>10$ \\
\hline
\end{tabular}

${ }^{a}$ Tablets did not float; ${ }^{b}$ Tablets disintegrated soon after they floated

It was observed that all the formulations containing HPMC (K4M or K15M) along with MCC had floating lag times $<30 \mathrm{~s}$. A similar result was observed for formulations containing HPMC (K4M or $\mathrm{K} 15 \mathrm{M})$ plus lactose except for formulations $\mathrm{C}_{3}$ and $\mathrm{D}_{3}$ which floated after $5.5 \mathrm{~min}$ and $50.8 \mathrm{~s}$, respectively. All these formulations remained buoyancy for $>10 \mathrm{~h}$. In contrast, none of the formulations containing tricalcium phosphate floated.

The results from buoyancy studies on formulation batch series $G$ showed that by increasing the amount of $\mathrm{NaCMC}$ and decreasing the amount of MCC, the time required for the tablets to float increased while the duration of floating decreased $(p<$ 0.05). Formulation $G_{1}$ which did not contain MCC did not float at all while formulation $G_{4}$ which had the lowest concentration of NaCMC floated rapidly; however, due to the low concentration of polymer it disintegrated soon after floatation. In case of formulation series $\mathrm{H}$, increasing HPMC K4M: NaCMC ratio has caused the tablets to float more quickly $(p<0.05)$. Formulation $\mathrm{H}_{1}$ with the highest amount of $\mathrm{NaCMC}$ floated for only 3 h.

\section{Drug release profile}

Figures 1 and 2 show the drug release profiles of HPMC/MCC matrix tablets of bupropion prepared from formulation series A, B. C, D and $\mathrm{H}_{2}-\mathrm{H}_{4}$.

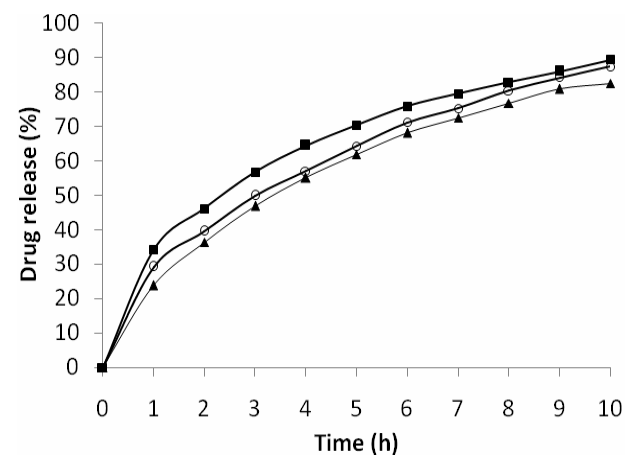

Figure 1: Effect of HPMC K4M content on bupropion $\mathrm{HCl}$ release from matrix tablets containing $\mathrm{MCC}$ in $0.1 \mathrm{M} \mathrm{HCl}$ at $37 \pm 0.5{ }^{\circ} \mathrm{C}$. $\square=$ $15 \%$ HPMC K15 $\left(B_{1}\right) ; \circ=20 \%$ HPMC K4M $\left(B_{2}\right)$; $\boldsymbol{\Delta}=25 \% \operatorname{HPMC~K} 4 \mathrm{M}\left(\mathrm{B}_{3}\right)$.

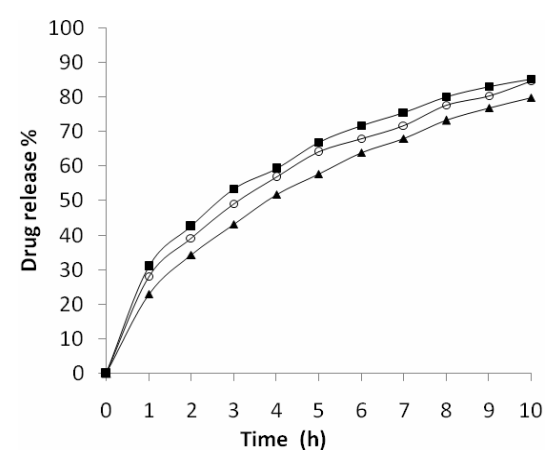

Figure 2: Effect of HPMC K15M content on bupropion $\mathrm{HCl}$ release from matrix tablets containing $\mathrm{MCC}$ in $0.1 \mathrm{M} \mathrm{HCl}$ at $37 \pm 0.5{ }^{\circ} \mathrm{C}$. $\mathbf{~ = ~}$

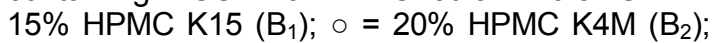
$\boldsymbol{\Delta}=25 \%$ HPMC K4M $\left(B_{3}\right)$.

Raising the amount of HPMC reduced drug release rate $(p<0.05)$. Formulation series $B$ 
containing HPMC K15M showed slower drug release rate than formulation series $A$ containing HPMC K4M.

Figures 3 and 4 present the release profiles of drug from HPMC/lactose matrix tablets of bupropion. Like in formulation series $A$ and $B$, drug release from formulation series $C$ and $D$ decreased as the content of HPMC increased. However, the effect of increasing HPMC content on drug release was more pronounced for tablets containing MCC than for those containing lactose.

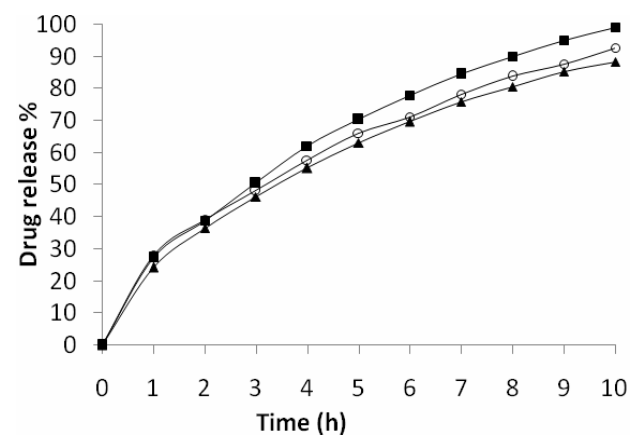

Figure 3: Effect of HPMC K4M content on bupropion $\mathrm{HCl}$ release from matrix tablets containing lactose in $0.1 \mathrm{M} \mathrm{HCl}$ at $37 \pm 0.5^{\circ} \mathrm{C}$. $\mathbf{=}=$ $15 \%$ HPMC K4M $\left(\mathrm{C}_{1}\right), \circ=20 \% \operatorname{HPMC~K4M~}\left(\mathrm{C}_{2}\right)$; $\boldsymbol{\Delta}=25 \% \operatorname{HPMC~K4M~}\left(\mathrm{C}_{3}\right)$

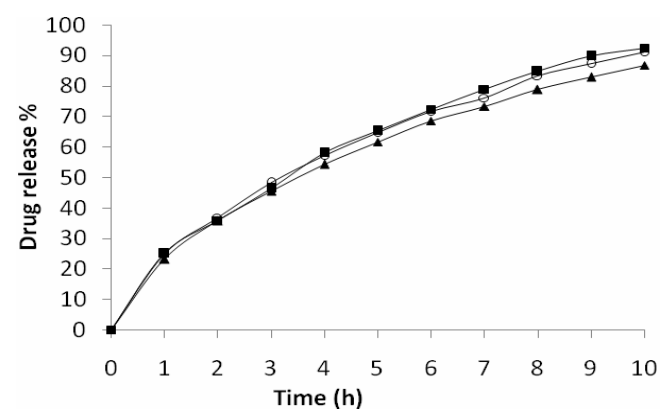

Figure 4: Effect of HPMC K15M content on bupropion $\mathrm{HCl}$ release from matrix tablets containing lactose in $0.1 \mathrm{M} \mathrm{HCl}$ at $37 \pm 0.5^{\circ} \mathrm{C}$. $\mathbf{~ = ~}$ $15 \%$ HPMC K15M $\left(D_{1}\right) ; \circ=20 \%$ HPMC K15M $\left(D_{2}\right) ; \boldsymbol{\Delta}=25 \% \operatorname{HPMC~K15M}\left(D_{3}\right)$

The release profile of bupropion $\mathrm{HCl}$ from tablets containing varying ratios of HPMC $\mathrm{K} 4 \mathrm{M}$ and $\mathrm{NaCMC}$ as the matrix is shown in
Figure 5. The difference between drug release from matrices containing 2:3 and 3:1 ratios of HPMC K4M: NaCMC, i.e., formulations $\mathrm{H}_{4}$ and $\mathrm{H}_{2}$, was significant $(p<$ 0.05)

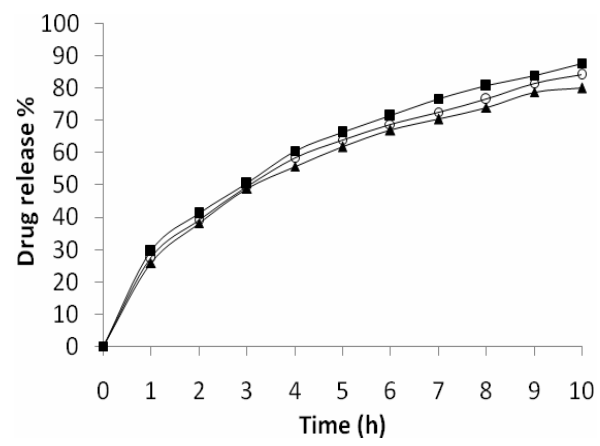

Figure 5: Effect of HPMC K4M:NaCMC ratio on bupropion $\mathrm{HCl}$ release from matrix tablets containing MCC in $0.1 \mathrm{M} \mathrm{HCl}$ at $37.0 \pm 0.5^{\circ} \mathrm{C}$. - =2:3 $\left(\mathrm{H}_{2}\right) ; \circ=1: 1\left(\mathrm{H}_{3}\right) ; \boldsymbol{\Delta}=3: 1\left(\mathrm{H}_{4}\right)$

\section{Release kinetics}

The values of kinetic rate constant (k), determination coefficient $\left(r^{2}\right)$ and release exponent $(n)$ are presented in Table 5 . The most appropriate model, based on the highest value of regression coefficient $\left(r^{2}\right)$, was Higuchi. Values of $n$ obtained from Korsemeyer-Peppas model were between 0.45 and 0.89 , indicating anomalous diffusion.

\section{DISCUSSION}

All the formulations had good physical properties. The low hardness of formulation $\mathrm{G}_{1}$ is due to the absence of MCC. The good floating ability of formulations series $A, B, C$ and $D$ is a result of the evolution of $\mathrm{CO}_{2}$ when sodium bicarbonate interacts with the dissolution medium which is acidic. Consequently entrapment of the gas $\left(\mathrm{CO}_{2}\right)$ inside the hydrated polymeric matrix lowers the density of the tablet and thus causes the dosage form to float.

Increasing the amount of polymer in the formulations prepared with MCC did not 
Table 5: Kinetic parameters for drug release from buproion $\mathrm{HCl}$ marix tablets.

\begin{tabular}{|c|c|c|c|c|c|c|c|c|c|c|c|c|c|c|c|c|}
\hline \multicolumn{2}{|c|}{$\begin{array}{c}\text { Kinetic } \\
\text { model }\end{array}$} & $A_{1}$ & $A_{2}$ & $A_{3}$ & $B_{1}$ & $B_{2}$ & $\mathrm{~B}_{3}$ & $C_{1}$ & $C_{2}$ & $C_{3}$ & $D_{1}$ & $D_{2}$ & $D_{3}$ & $\mathrm{H}_{2}$ & $\mathrm{H}_{3}$ & $\mathrm{H}_{4}$ \\
\hline \multirow{2}{*}{$\begin{array}{l}\text { Zero- } \\
\text { order }\end{array}$} & $\mathrm{r}^{2}$ & $\begin{array}{c}0.84 \\
9\end{array}$ & $\begin{array}{c}0.90 \\
4\end{array}$ & $\begin{array}{c}0.90 \\
8\end{array}$ & $\begin{array}{c}0.86 \\
5\end{array}$ & 0.892 & $\begin{array}{c}0.92 \\
0\end{array}$ & $\begin{array}{c}0.93 \\
6\end{array}$ & $\begin{array}{c}0.92 \\
9\end{array}$ & $\begin{array}{c}0.93 \\
2\end{array}$ & $\begin{array}{c}0.94 \\
0\end{array}$ & $\begin{array}{c}0.93 \\
2\end{array}$ & $\begin{array}{c}0.93 \\
2\end{array}$ & $\begin{array}{c}0.89 \\
0\end{array}$ & $\begin{array}{c}0.88 \\
6\end{array}$ & $\begin{array}{c}0.88 \\
1\end{array}$ \\
\hline & $\begin{array}{l}\mathbf{K}_{\mathbf{0}} \\
\left(\mathrm{h}^{-1}\right)\end{array}$ & $\begin{array}{c}7.49 \\
6\end{array}$ & $\begin{array}{c}7.66 \\
2\end{array}$ & $\begin{array}{c}7.50 \\
4\end{array}$ & $\begin{array}{c}7.29 \\
6\end{array}$ & 7.305 & $\begin{array}{c}7.20 \\
7\end{array}$ & $\begin{array}{c}9.12 \\
6\end{array}$ & $\begin{array}{c}8.25 \\
6\end{array}$ & $\begin{array}{c}8.10 \\
5\end{array}$ & $\begin{array}{c}8.60 \\
5\end{array}$ & $\begin{array}{c}8.31 \\
1\end{array}$ & $\begin{array}{c}7.92 \\
4\end{array}$ & $\begin{array}{c}7.62 \\
2\end{array}$ & $\begin{array}{c}7.30 \\
1\end{array}$ & $\begin{array}{c}7.02 \\
5\end{array}$ \\
\hline \multirow{2}{*}{$\begin{array}{l}\text { First- } \\
\text { order }\end{array}$} & $r^{2}$ & $\begin{array}{c}0.99 \\
1\end{array}$ & $\begin{array}{c}0.99 \\
5\end{array}$ & $\begin{array}{c}0.99 \\
5\end{array}$ & $\begin{array}{c}0.98 \\
9\end{array}$ & 0.991 & $\begin{array}{c}0.99 \\
5\end{array}$ & $\begin{array}{c}0.87 \\
3\end{array}$ & $\begin{array}{c}0.97 \\
7\end{array}$ & $\begin{array}{c}0.99 \\
6\end{array}$ & $\begin{array}{c}0.98 \\
4\end{array}$ & $\begin{array}{c}0.98 \\
7\end{array}$ & $\begin{array}{c}0.99 \\
6\end{array}$ & $\begin{array}{c}0.99 \\
5\end{array}$ & $\begin{array}{c}0.99 \\
1\end{array}$ & $\begin{array}{c}0.98 \\
5\end{array}$ \\
\hline & $\begin{array}{l}\mathbf{K}_{1} \\
\left(\mathrm{~h}^{-1}\right)\end{array}$ & $\begin{array}{c}0.20 \\
6\end{array}$ & $\begin{array}{c}0.19 \\
4\end{array}$ & $\begin{array}{c}0.17 \\
1\end{array}$ & $\begin{array}{c}0.18 \\
1\end{array}$ & 0.172 & $\begin{array}{c}0.15 \\
3\end{array}$ & $\begin{array}{c}0.38 \\
4\end{array}$ & $\begin{array}{c}0.23 \\
7\end{array}$ & $\begin{array}{c}0.20 \\
7\end{array}$ & $\begin{array}{c}0.24 \\
9\end{array}$ & $\begin{array}{c}0.22 \\
8\end{array}$ & $\begin{array}{c}0.19 \\
3\end{array}$ & $\begin{array}{c}0.19 \\
6\end{array}$ & $\begin{array}{c}0.17 \\
2\end{array}$ & $\begin{array}{c}0.15 \\
4\end{array}$ \\
\hline \multirow{2}{*}{$\begin{array}{l}\text { Higuc } \\
\text { hi }\end{array}$} & $r^{2}$ & $\begin{array}{l}0.99 \\
8\end{array}$ & $\begin{array}{l}0.99 \\
8\end{array}$ & $\begin{array}{c}0.99 \\
9\end{array}$ & $\begin{array}{c}0.99 \\
7\end{array}$ & 0.997 & $\begin{array}{c}0.99 \\
8\end{array}$ & $\begin{array}{c}0.98 \\
9\end{array}$ & $\begin{array}{c}0.99 \\
4\end{array}$ & $\begin{array}{c}0.99 \\
9\end{array}$ & $\begin{array}{c}0.99 \\
2\end{array}$ & $\begin{array}{c}0.99 \\
8\end{array}$ & $\begin{array}{c}0.99 \\
9\end{array}$ & $\begin{array}{c}0.99 \\
7\end{array}$ & $\begin{array}{c}0.99 \\
6\end{array}$ & $\begin{array}{c}0.99 \\
6\end{array}$ \\
\hline & $\begin{array}{l}\mathbf{K}_{\mathbf{H}} \\
\left(\mathrm{h}^{-}\right. \\
t_{12}\end{array}$ & $\begin{array}{c}29.7 \\
4\end{array}$ & $\begin{array}{c}28.5 \\
1\end{array}$ & $\begin{array}{c}30.7 \\
0\end{array}$ & $\begin{array}{c}29.0 \\
3\end{array}$ & 28.28 & $\begin{array}{c}27.8 \\
6\end{array}$ & $\begin{array}{c}34.6 \\
9\end{array}$ & $\begin{array}{c}30.5 \\
2\end{array}$ & $\begin{array}{c}31.5 \\
3\end{array}$ & $\begin{array}{c}33.2 \\
4\end{array}$ & $\begin{array}{c}32.5 \\
5\end{array}$ & $\begin{array}{c}31.3 \\
5\end{array}$ & $\begin{array}{c}30.2 \\
7\end{array}$ & $\begin{array}{c}29.0 \\
5\end{array}$ & $\begin{array}{c}28.5 \\
2\end{array}$ \\
\hline $\begin{array}{c}\text { Hixon } \\
-\end{array}$ & $r^{2}$ & $\begin{array}{c}0.96 \\
4\end{array}$ & $\begin{array}{c}0.98 \\
4\end{array}$ & $\begin{array}{c}0.97 \\
8\end{array}$ & $\begin{array}{c}0.96 \\
4\end{array}$ & 0.974 & $\begin{array}{c}0.98 \\
2\end{array}$ & $\begin{array}{c}0.98 \\
1\end{array}$ & $\begin{array}{c}0.99 \\
2\end{array}$ & $\begin{array}{c}0.99 \\
4\end{array}$ & $\begin{array}{c}0.99 \\
7\end{array}$ & $\begin{array}{c}0.99 \\
5\end{array}$ & $\begin{array}{c}0.99 \\
3\end{array}$ & $\begin{array}{c}0.97 \\
9\end{array}$ & $\begin{array}{c}0.97 \\
1\end{array}$ & $\begin{array}{c}0.96 \\
1\end{array}$ \\
\hline $\begin{array}{c}\text { Crowe } \\
\text { II }\end{array}$ & $\begin{array}{l}\mathbf{K}_{\mathrm{HC}} \\
\left(\mathrm{h}^{-1}\right)\end{array}$ & $\begin{array}{c}0.22 \\
0\end{array}$ & $\begin{array}{c}0.21 \\
5\end{array}$ & $\begin{array}{c}0.19 \\
7\end{array}$ & $\begin{array}{c}0.20 \\
2\end{array}$ & 0.196 & $\begin{array}{c}0.18 \\
1\end{array}$ & $\begin{array}{c}0.33 \\
1\end{array}$ & $\begin{array}{c}0.24 \\
8\end{array}$ & $\begin{array}{c}0.22 \\
7\end{array}$ & $\begin{array}{c}0.25 \\
9\end{array}$ & $\begin{array}{c}0.24 \\
3\end{array}$ & $\begin{array}{c}0.21 \\
6\end{array}$ & $\begin{array}{c}0.21 \\
5\end{array}$ & $\begin{array}{c}0.19 \\
5\end{array}$ & $\begin{array}{c}0.18 \\
0\end{array}$ \\
\hline Рeppa & $r^{2}$ & $\begin{array}{c}0.99 \\
9\end{array}$ & $\begin{array}{c}0.99 \\
6\end{array}$ & $\begin{array}{c}0.99 \\
9\end{array}$ & $\begin{array}{c}0.99 \\
6\end{array}$ & 0.998 & $\begin{array}{c}0.99 \\
9\end{array}$ & $\begin{array}{c}0.99 \\
5\end{array}$ & $\begin{array}{c}0.99 \\
6\end{array}$ & $\begin{array}{c}0.99 \\
9\end{array}$ & $\begin{array}{c}0.99 \\
2\end{array}$ & $\begin{array}{c}0.99 \\
8\end{array}$ & $\begin{array}{c}0.99 \\
9\end{array}$ & $\begin{array}{c}0.99 \\
7\end{array}$ & $\begin{array}{c}0.99 \\
8\end{array}$ & $\begin{array}{c}0.99 \\
8\end{array}$ \\
\hline s & $\mathrm{n}$ & $\begin{array}{c}0.48 \\
5\end{array}$ & $\begin{array}{c}0.48 \\
5\end{array}$ & $\begin{array}{c}0.60 \\
9\end{array}$ & $\begin{array}{c}0.47 \\
7\end{array}$ & 0.511 & $\begin{array}{c}0.57 \\
7\end{array}$ & $\begin{array}{c}0.55 \\
6\end{array}$ & $\begin{array}{c}0.50 \\
9\end{array}$ & $\begin{array}{c}0.59 \\
2\end{array}$ & $\begin{array}{c}0.59 \\
7\end{array}$ & $\begin{array}{c}0.60 \\
1\end{array}$ & $\begin{array}{c}0.61 \\
4\end{array}$ & $\begin{array}{c}0.51 \\
1\end{array}$ & $\begin{array}{c}0.53 \\
8\end{array}$ & $\begin{array}{c}0.56 \\
2\end{array}$ \\
\hline
\end{tabular}

influence floating lag time of the tablets significantly. However, in formulations containing lactose, floating lag time increased when the content of HPMC was raised to 100 mg. This may be attributed to the structural properties of MCC including swellable and porous structure and also low density of particles [14-16]. MCC gave such good floating properties to the formulations that increasing the polymer to sodium bicarbonate ratio in formulation series $A$ and $B$ did not increase floating lag time substantially. In contrast, increasing the polymer content to $100 \mathrm{mg}$ in formulation series $C$ and $D$, where lactose was used in place of MCC, led to increase in floating lag time due to higher water absorption by the polymer making the matrix denser.

Formulation series $\mathrm{E}$ and $\mathrm{F}$ did not float due to the insoluble nature of tricalcium phosphate which also imparted low porosity to the tablet matrix. Furthermore, the high density of tricalcium phosphate would also have enhanced the overall tablet density to a level above that of the simulated gastric fluid with the result that the tablets failed to float throughout the test period.
Formulation series $\mathrm{G}$ prepared with $\mathrm{NaCMC}$ did not show good floating properties because $\mathrm{NaCMC}$ is a hydrophilic polymer with a high water absorption capacity and therefore, the tablets were weighed down in the medium by the absorbed fluid. Moreover, the gel layer formed by the polymer seems to be lower in strength than that formed by HPMC and, therefore, could not entrap the evolved gas efficiently. This is why increasing the proportion of $\mathrm{NaCMC}$ in its mixture with HPMC K4M (formulation series $\mathrm{H}$ ), resulted in high floating lag time before the tablets floated.

The reduction in drug release rate as polymer (HPMC) content or viscosity increased may be attributed to stronger gel formation. Highly viscous gels cause retardation of drug release $[17,18]$. Burst effect was observed in all the formulations due to rapid drug dissolution from the surface of the tablets. This effect was more pronounced at lower polymer concentrations. Furthermore, formulations containing MCC exhibited greater burst effect than those containing lactose, especially at a low polymer concentration (15\%) because of the disintegrating and swelling properties of 
former. Subsequently, drug release from the tablets containing lactose accelerated over that from tablets formulated with MCC which is insoluble and therefore might have hindered drug release from the tablets. Increase in the proportion of HPMC K4M relative to that of $\mathrm{NaCMC}$ led to slower drug release because HPMC has capacity to form a more stable gel than $\mathrm{NaCMC}$.

When the release data were fitted to various kinetic models, the lowest regression coefficient $\left(r^{2}\right)$ values were yielded by the zero order model for a majority of the formulations. On the other hand, a majority of the formulations fitted best to the Higuchi model. Thus, drug release was principally controlled by diffusion. For formulations containing MCC, drug release might also have been dependent on drug concentration based on first order $r^{2}$ values. Similarly, formulations containing lactose showed relatively high Hixon-Crowel $r^{2}$ values, indicating a change in the surface and diameter of the tablets with progressive dissolution of the matrix as a function of time. Thus, when lactose is employed as a filler, changes in tablet surface and diameter is more likely to occur due to the soluble nature of lactose.

Generally, the $n$ values from the KorsemeyerPeppas relationship for all the formulations were $>0.45$ which is indicative of drug release mechanism based on diffusion, swelling and erosion. Increasing the relative proportion of the polymer yielded higher $n$ values, especially for formulation series of $A$ and B. For both series, drug release at lower polymer contents was mainly governed by diffusion, while at higher polymer contents, the release mechanism shifted to anomalous transport with both diffusion and erosion controlling release.

\section{CONCLUSION}

Floating tablets of bupropion $\mathrm{HCl}$ were successfully developed in this study. HPMC is a matrix material for designing floating tablets and appropriate blending with $\mathrm{NaCMC}$ can yield floating tablets with suitable drug release and swelling characteristics. However, further studies, including in vivo investigations, are necessary to confirm the findings of this work.

\section{REFERENCES}

1. Choi B, Fark H, Hwang SJ, Park JB. Preparation of alginate beads for floating drug delivery system; effects of $\mathrm{CO}_{2}$ gas-forming agents. Int J Pharm 2002; 239: 81-91.

2. Streubel $A$, Siepmann $J$, Bodmeier $R$. Gastroretentive drug delivery system. Expert Opin Drug Deliv 2006; 3(2): 217-33.

3. Whitehead L, Fell JT, Collett JH, Sharma HL, Smith AM. Floating dosage forms: an in vivo study demonstrating prolonged gastric retention. $J$ Control Rel 1998; 55: 3-12.

4. Singh BN, Kim KH. Floating drug delivery systems: an approach to oral controlled drug delivery via gastric retention. J Control Rel 2000; 63: 235259.

5. Ferris RM, Cooper BR, Mechanism of antidepressant activity of bupropion. J Clin Psychiatry 1993; 11(1): 2-14.

6. Rosa M, Zia H, Rhodes T. Dosing and testing invitro of a bioadhesive and floating drug delivery system for oral application. Int $\mathrm{J}$ Pharm 1994; 105: 65-70.

7. Najib N, Suleiman M. The kinetics of drug release from ethyl cellulose solid dispersion. Drug Dev Ind Pharm 1985; 11: 2169-2181.

8. Desai Sj, Singh $P$, Simonelli AP, Higuchi WI. Investigation of factors influencing release of solid drug dispersed in wax matrices 3. Quantitative studies involving polyethylene plastic matrix. J Pharm Sci 1966; 55: 12301234.

9. Higuchi T. Mechanism of sustained action medication. Theoretical analysis of rate of release of solid drugs dispersed in solid matrices. J Pharm Sci 1963; 52: 1145-1149.

10. Hixon AW, Crowell JH. Dependence of reaction velocity upon surface and agitation. Ind Eng Chem 1931; 23: 923-931.

11. Korsmeyer RW, Gurny $R$, Doelker $E$, Buri $P$, Peppas NA. Mechanisms of solute release from porous hydrophilic polymers. Int $J$ Pharm 1983; 15: 25-35.

12. Siepmann J, Peppas NA. Modeling of drug release from delivery systems based on hydroxypropyl methylcellulose (HPMC). Adv Drug Deliv Rev 2001; 48: 139-157.

13. United States Pharmacopeia, National Formulary USP 23. NF18, Rockville, 1995: 1216.

14. Tadros MI. Controlled-release effervescent floating matrix tablets of ciprofloxacin hydrochloride: Development, optimization and in vitro-in vivo 
evaluation in healthy human volunteers. Eur $J$ Pharm Biopharm 2010; 74: 332-339.

15. Baumgartner $S$, Kristl J, Vrecer $F$, Vodopivee $P$, Zorko B. Optimization of floating matrix tablets and evaluation of their gastric residence time. Int J Pharm 2000; 195: 125-135.

16. Sheela NBS, Damodharan N, Madhukar S, Surekha I, Rao TS. Formulation and evaluation of clarithromycin gastroretentive dosage form. Int J Pharm Pharm Sci 2010; 2(3): 48-55.
17. Viral F, Patel NM. Statistical evaluation of influence of viscosity and content polymer on dipyridamole release from floating matrix tablets: A technical note. AAPS PharmSciTech 2007; 8(3): E1-E5.

18. Garg R, Gupta G. Preparation and evaluation of gastroretentive floating tablets of silymarin. Chem Pharm Bull 2009; 57(6): 545-549. 